General paper

\title{
Effect of Air-oxidation on the Thermal Diffusivity of the Nuclear Grade 2-dimensional Carbon Fiber Reinforced Carbon/carbon Composite
}

\author{
Toshiaki Sogabe, Masahiro IsHIHARA, Shin-ichi BABA, Yukio TACHIBANA, \\ Masatoshi YAMAJI, Tatsuo IYOKU, Taiji HoSHIYA \\ Oarai Research Establishment, Japan Atomic Energy Research Institute, \\ 3607 Oarai-machi, Higashiibaraki-gun, Ibaraki-ken, 311-1394, Japan
}

\begin{abstract}
D-C/C composite is one of the promising materials as a next-generation core material in gas-cooled reactors. Effect of air-oxidation on the thermal diffusivity of the $2 \mathrm{D}-\mathrm{C} / \mathrm{C}$ composite was investigated in this study. Tested composite consists of $6 \mathrm{~K}$ plain-woven fabrics with PAN-based carbon fiber and graphite matrix. Final heat-treatment of around $3073 \mathrm{~K}$ was applied to the composite. The $\mathrm{C} / \mathrm{C}$ composite specimens for measurement of thermal diffusivity were oxidized from 1 to $11 \%$ weight loss in air at $823 \mathrm{~K}$. Oxidation loss of the composite preferentially occurred at matrix part near the fiber bundles, and then occurred at fiber bundles. This composite exhibited large anisotropy in thermal diffusivity, higher value for parallel to lamina direction and lower value for perpendicular, e.g. thermal diffusivity of $1.1 \mathrm{~cm}^{2} / \mathrm{s}$ for parallel to lamina and $0.2 \mathrm{~cm}^{2} / \mathrm{s}$ for perpendicular at room temperature. Thermal diffusivity at room temperature declined $10 \sim 20 \%$ for parallel to lamina direction and $5 \sim 9 \%$ for that of perpendicular within $11 \%$ weight loss by oxidation. Thermal diffusivity tended to decrease gradually as the increase of oxidation loss in parallel to lamina, however, it decreased in the beginning of oxidation pretty much and not so changed by further oxidation loss in perpendicular to lamina. The different behavior due to air-oxidation on the thermal diffusivity in two directions was discussed from the fiber and/or matrix texture changes due to air-oxidation. Change in thermal conductivity under oxidation condition was also estimated from the obtained thermal diffusivity.
\end{abstract}

Key words: Carbon fiber reinforced carbon-carbon composite, 2D-C/C composite, Gas-cooled reactor, Air-oxidation, Thermal diffusivity, Tthermal conductivity

\section{INTRODUCTION}

Now, $\mathrm{C} / \mathrm{C}$ composites are widely used in the various industries such as trays, jigs and fasteners for heat-treatment furnaces and crucibles for silicon single crystal production due to their excellent thermal stability as well as high strength. In the nuclear engineering field, $\mathrm{C} / \mathrm{C}$ composites are also thought to be one of the attractive materials for high temperature components in High Temperature Gas-cooled Reactors (HTGR) and fusion reactors. In the HTGR application, systematic studies on a 2-dimentional C/C composite (2D-C/C composite) have been carried out in Japan Atomic Energy Research Institute (JAERI) aiming at the development of a control rod sheath for next-generation HTGRs [1-5].

From a view point of application, air-oxidation of the 2D-C/C composite is one of the key research subjects in design and safety analyses in the HTGRs. Research on thermal diffusivity affected by air-oxidation is important in order to assess the structural integrity at an air-ingress accident. However, no research on change in the thermal diffusivity due to the air-oxidation of the $2 \mathrm{D}-\mathrm{C} / \mathrm{C}$ composite is reported.

In the present paper, effect of air-oxidation on the thermal diffusivity of a nuclear grade $2 \mathrm{D}-\mathrm{C} / \mathrm{C}$ composite is studied.

\section{EXPERIMENTAL}

\subsection{Material}

A 2D-C/C composite (CX-270G [6], fabricated by TOYO TANSO Co., Ltd.) was used in this study. This composite consists of $6 \mathrm{~K}$ plain-woven fabrics of PAN-based carbon fiber and graphite matrix.

In the fabrication of this composite, prepreg was prepared with the plain-woven fabrics and phenolic resin. Then, a prepreg stack was placed in a hot-press and was heated up around $473 \mathrm{~K}$. Thus prepared preform is in the stage of carbon fiber reinforced plastic, CFRP. The CFRP was heat-treated at more than $1073 \mathrm{~K}$ to carbonize the plastic. Then the pitch impregnation and heat-treatment processes were repeated alternatively several times to achieve the carbonized stuff high density. Eventually, carbon fiber fabrics are stuck together with the sheath resin-derived matrix, and some pores in the composite are impregnated with the pitch-derived matrix. Final heat-treatment of the composite was carried out at around $3073 \mathrm{~K}$ for graphitization. In the composite, volume fraction of the fiber $\left(V_{f}\right)$ is about $50 \%$ and open porosity estimated by mercury porosimetry is around $15 \%$.

Furthermore, a purification process was conducted to eliminate impurities because it is very important for the nuclear material to avoid activation as well as to reduce oxidation loss. Achieved impurity level was less than 5 
ppm.

Material properties of the tested composite are summarized in Table 1. As for mechanical properties, the $2-\mathrm{D} C / \mathrm{C}$ composite has rather low interlayer or interlamina shear strength. This composite exhibits much the same anisotropic thermal properties as reported in other $2 \mathrm{D}-\mathrm{C} / \mathrm{C}$ composite [7]. Thermal expansion coefficient of parallel to lamina or direction of along the fabrics is almost governed by the a-axis of the fiber and graphite matrix so that the value became quite low. On the other hand, that of perpendicular to lamina or across the fabrics is mostly affected by the expansion of c-axis direction of the fiber and graphite matrix so that the value appeared to be much higher than that of parallel to lamina.

Table 1 Physical properties of tested $\mathrm{C} / \mathrm{C}$ composite at room temperature.

\begin{tabular}{ccccccccc}
\hline Grade & $\begin{array}{c}\text { Bulk- } \\
\text { density } \\
{\left[\mathrm{g} / \mathrm{cm}^{3}\right]}\end{array}$ & $\begin{array}{c}\text { Electrical } \\
\text { resistivity } \\
{[\mu \Omega \cdot \mathrm{m}]}\end{array}$ & $\begin{array}{c}\text { Bending } \\
\text { strength } \\
{[\mathrm{MPa}]}\end{array}$ & $\begin{array}{c}\text { Tensile } \\
\text { strength } \\
{[\mathrm{MPa}]}\end{array}$ & $\begin{array}{c}\text { Compressive } \\
\text { strength } \\
{[\mathrm{MPa}]}\end{array}$ & $\begin{array}{c}\text { Intrerlayer shear } \\
\text { strength } \\
{[\mathrm{MPa}]}\end{array}$ & $\begin{array}{c}\text { Elastic } \\
\text { modulus } \\
{[\mathrm{GPa}]}\end{array}$ & $\begin{array}{c}\text { Thermal expansion } \\
\text { coefficient }\end{array}$ \\
{$\left[10^{-6} / \mathrm{K}\right][\mathrm{RT} \sim 1273 \mathrm{~K})$} \\
\hline $2 \mathrm{D}-\mathrm{C} / \mathrm{C}$ & 1.63 & $\begin{array}{c}6.5 \\
(/ /)\end{array}$ & $\begin{array}{c}133 \\
(\perp)\end{array}$ & $\begin{array}{c}167 \\
(/ /)\end{array}$ & $69(/ /) / 89(\perp)$ & 5.7 & $\begin{array}{c}81 \\
(/ /)\end{array}$ & $0.2(/ /) / 10.8(\perp)$ \\
\hline
\end{tabular}

(//) : Parallel to lamina, $(\perp)$ : Perpendicular to lamina.

\subsection{Specimens for Thermal Diffusivity Measurement}

Specimen with thin thickness is preferable to measure the thermal diffusivity by a laser-flash method [8]. However, the thin specimen causes measurement error due to laser-pulse width, inhomogeneous of the specimen etc. [8] For graphite and $\mathrm{C} / \mathrm{C}$ composite materials, disk-shaped specimens with $1 \mathrm{~mm}$ to $2 \mathrm{~mm}$ thickness were normally used [9]. Therefore, in this study, disk-shaped specimens of $10 \mathrm{~mm}$ in diameter with $2 \mathrm{~mm}$ in thickness were used to measure the thermal diffusivity. Specimens were cut out from a $\mathrm{C} / \mathrm{C}$ composite block in two directions as shown in Fig.1; the one is parallel to lamina and the other is perpendicular to lamina.

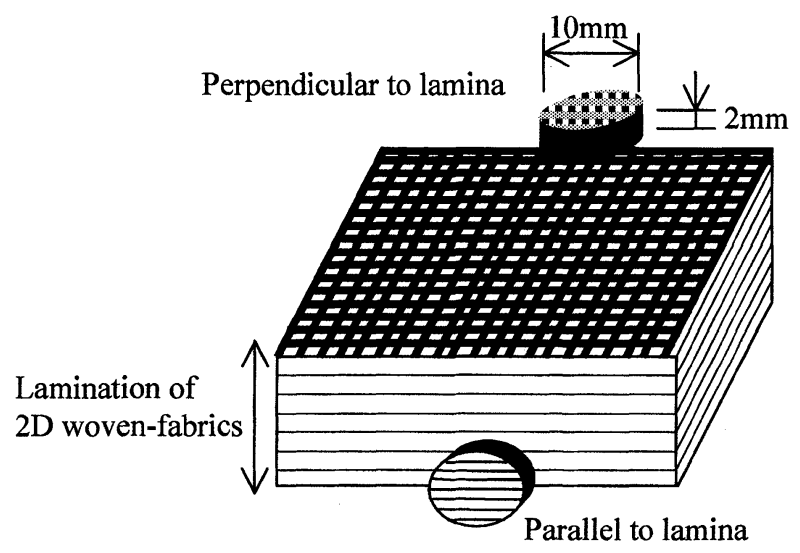

Fig.1. Cutting out of test specimens from a 2D-C/C composite block.

\subsection{Air-oxidation Treatment}

Air-oxidation treatment was carried out in an electric furnace under stagnant air at $823 \mathrm{~K}$; this temperature corresponds to a chemical-reaction controlled oxidation so as to oxidize uniformly in the whole body of the specimen. Oxidation loss was estimated from the measured weights before and after oxidation. Various specimens with different oxidation loss between around 1 and 11 mass $\%$ were prepared by controlling the air-oxidation time. Oxidation loss was estimated from the Eq. (1). Here, weight loss by air-oxidation is referred to as oxidation loss,

$$
B(\operatorname{mass} \%)=\left\{\left(W_{1}-W_{2}\right) / W_{1}\right\} \times 100,
$$

where $W_{1}$ and $W_{2}$ are the weights before and after oxidation, respectively.

\subsection{Microstructural Observation}

Surfaces of specimens were observed by SEM, Scanning Electron Microscope (HITACHI S-3000N), and laser-microscope (KEYENCE VK-8550) to clarify the fiber and/or matrix change due to oxidation.

\subsection{Measurement of Thermal Diffusivity}

Thermal diffusivity of the specimens was measured by a laser-flash method using an apparatus of ULVAC Inc. Model TC-7000. Measured temperature range was from room temperature to $1673 \mathrm{~K}$ under vacuum condition at $10^{-1} \sim 10^{-3} \mathrm{~Pa}$. Maximum energy of $10 \mathrm{~J}$ was dissipated from Nd-glass laser to one surface of the disk-shaped specimen. Temperature of the back surface of the specimen was measured by In-Sb non-contact temperature-sensor. Thermal diffusivity was determined by so-called $t_{1 / 2}$ method [10] using

$$
\alpha=1.38 L^{2} /\left(\pi^{2} t_{1 / 2}\right),
$$

where $\alpha$ is the thermal diffusivity $\left(\mathrm{cm}^{2} / \mathrm{s}\right), L$ the thickness $(\mathrm{cm}), t_{1 / 2}$ the time required for the back surface to reach half of the maximum temperature rise (s).

\subsection{Estimation of Thermal Conductivity}

Thermal conductivity was estimated by

$$
\lambda=\alpha \rho C \mathrm{p},
$$

where $\lambda$ is the thermal conductivity $(\mathrm{W} / \mathrm{m} \cdot \mathrm{K}), \rho$ the 
bulk-density of the composite $\left(\mathrm{g} / \mathrm{cm}^{3}\right)$ and $\mathrm{Cp}$ the heat capacity of the specimen $(\mathrm{J} / \mathrm{K} \cdot \mathrm{kg})$. In this study, used value of the heat capacity was that of graphite [11].

\section{RESULTS ANI DISCUSSION}

\subsection{Microstructural Observation}

Figure 2 shows the SEM micrographs of non-oxidized and after 2.2, 5.5 and 10.8 mass\% oxidized specimens at cross sections of the lamina.

It is well known that the air-oxidation of the 2D-C/C composite proceeds according to the following reaction at low temperatures below around 923K [12],

$$
2 \mathrm{C}(\mathrm{s})+\mathrm{O}_{2} \rightarrow 2 \mathrm{CO}(\mathrm{g}) .
$$

It is also well known that the oxidation strongly depends on the impurities such as iron or vanadium, and such impurity elements often create craters or etch pits around impurities [13]. No obvious non-uniform oxidation by impurities was observed by SEM observations as shown in Fig.2. This is though to be the result of low impurity content of the 2D-C/C composite [6].

In a 2.2 mass \% oxidation in Fig.2, a little loss of matrix part near the fiber bundles was observed. In a 5.5 mass $\%$ oxidation, apparent loss of matrix was observed but loss of fiber was not clearly observed. In a 10.8 mass $\%$ oxidation, it was clearly observed that fibers became rather thin. Namely, oxidation of the matrix part near the fiber bundle and wall surface of the open pore occurred first, and next, fiber part oxidized after certain amount of elimination of the matrix. This is considered to be as follows; Matrix part is more reactive than fiber because the carbon fiber does not have open porosity and dangling bonds appeared to surface. The reason why the oxidation first took place interface between the fiber and the matrix in $2 \mathrm{D}-\mathrm{C} / \mathrm{C}$ composite is considered to be that the fiber bundle provides pathways for the rapid diffusion of the oxygen into the composite interior [14].

Top views of fiber cloths surface of non-oxidized and 5.1 mass $\%$ oxidized specimens observed by Laser -microscope are shown in Fig.3. Depth profile of the surface for line A-A is also shown. Scanning of surface roughness was focused on one fiber bundle in each sample. Loss of matrix in fiber bundle can be clearly observed as shown in Fig.3 (b); namely, it is found that the matrix part on the fiber oxidized first without fiber oxidation. Undulation range of the bundle, which means the range between maximum and minimum levels of undulation, changed from $7 \mu \mathrm{m}$ of non-oxidized to 14 $\mu \mathrm{m}$ of 5.1 mass $\%$ oxidized.

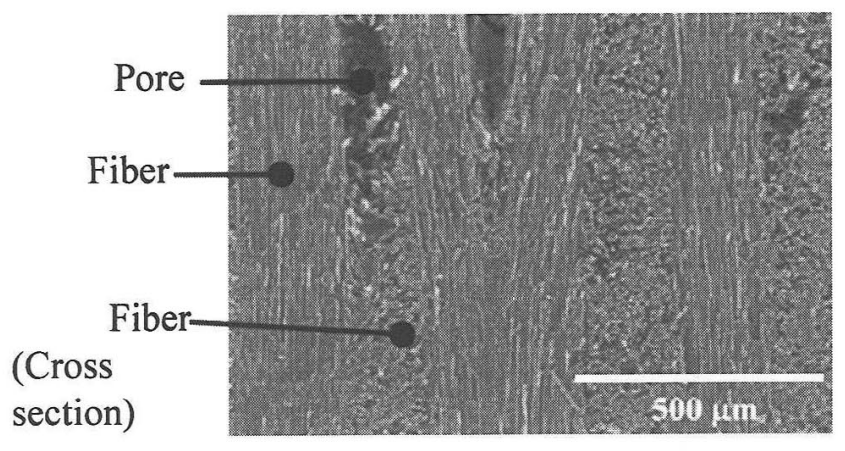

Non-oxidized

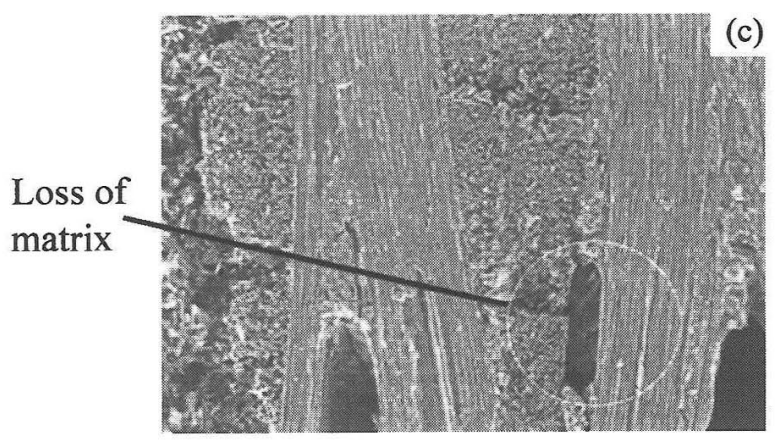

5.5 mass $\%$ oxidized

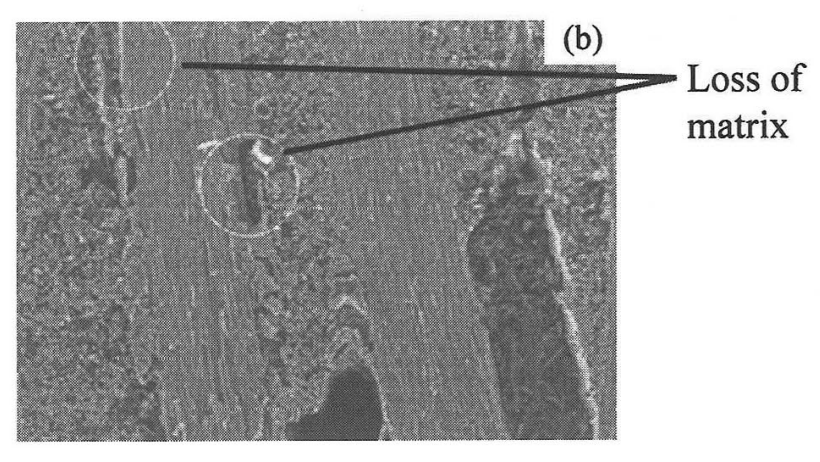

2.2 mass $\%$ oxidized

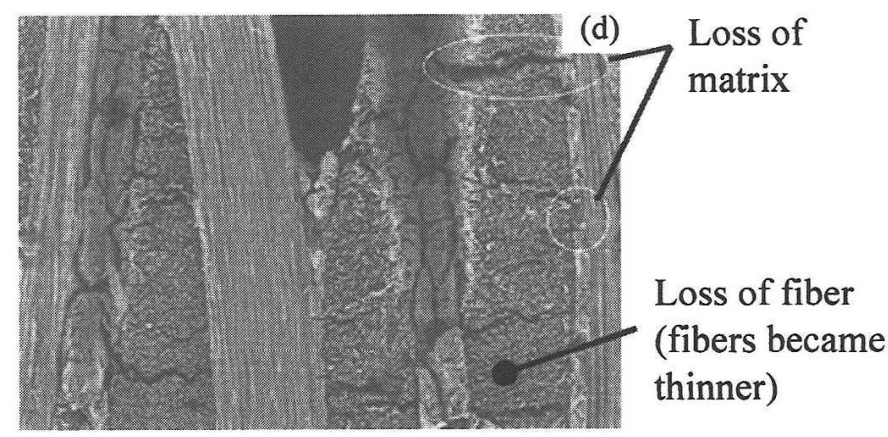

10.8 mass $\%$ oxidized

Fig.2. SEM micrographs of cross sections of lamina of the $2 \mathrm{D}-\mathrm{C} / \mathrm{C}$ composite. $\quad$ (a) As-received (b) $2.2 \mathrm{mass} \%$

(c) 5.5 mass $\%$ and (d) 10.8 mass $\%$ oxidized in air at $873 \mathrm{~K}$. A scale bar indicates $500 \mu \mathrm{m}$. 

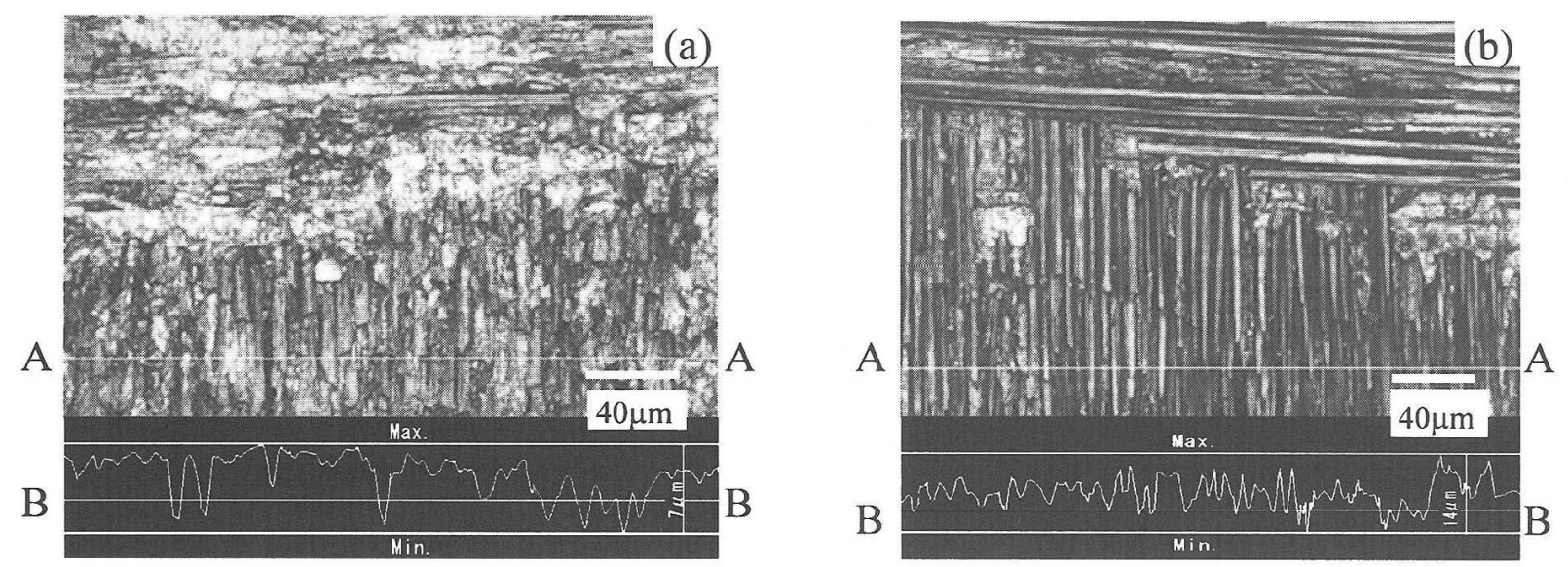

Fig.3. Laser-microscope observations of fiber bundle surface of the $2 \mathrm{D}-\mathrm{C} / \mathrm{C}$ composite. Surface roughness for line A-A is also shown in each micrograph. Line B-B shows arbitrary levels. (a) Non-oxidized and (b) 5.1 mass \% oxidized.

\subsection{Temperature Dependence of Thermal Diffusivity}

Temperature dependence of thermal diffusivity of the non-oxidized and 10 mass $\%$ oxidized $2 \mathrm{D}-\mathrm{C} / \mathrm{C}$ composites in both parallel and perpendicular to lamina is shown in Fig.4.

Thermal diffusivity decreased exponentially as the increase of temperature in both directions as naturally observed in graphite [15]. Large anisotropy in thermal diffusivity was observed in this composite. These values in parallel to lamina direction are about 5 to 6

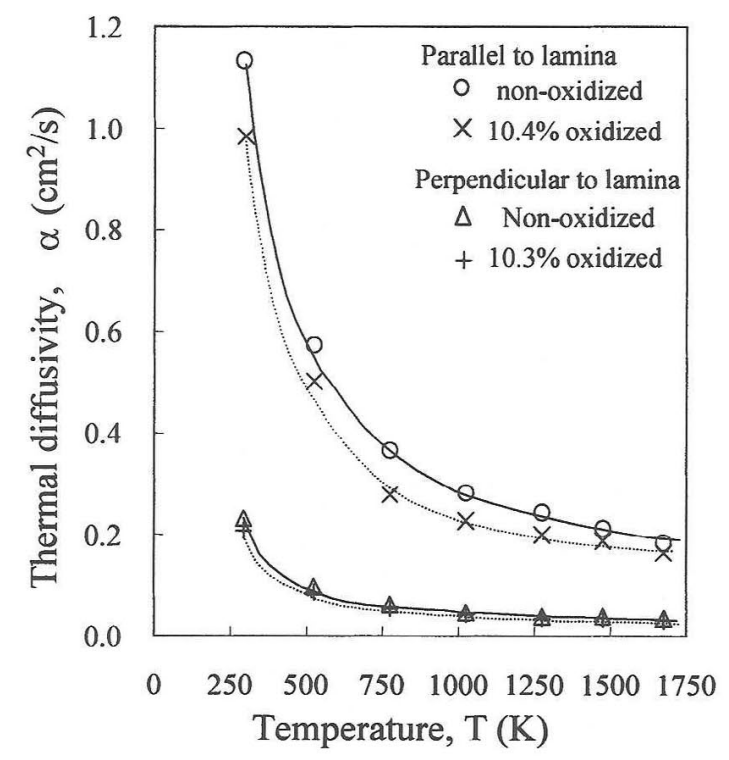

Fig.4. Temperature dependence of thermal diffusivity of 2D-C/C composite before and after 10 mass $\%$ oxidation in both parallel and perpendicular to lamina. times larger than those of perpendicular throughout measured temperature range. Existence of this anisotropy is simply explained by taking into account of laminar texture of this composite, i.e., the a-axis of the hexagonal graphite layers is aligned in parallel to lamina in both fiber and matrix.

In Fig.4, thermal diffusivity at room temperature decreased from $1.13 \mathrm{~cm}^{2} / \mathrm{s}$ to $0.99 \mathrm{~cm}^{2} / \mathrm{s}$ for parallel to lamina, and decreased from $0.23 \mathrm{~cm}^{2} / \mathrm{s}$ to $0.21 \mathrm{~cm}^{2} / \mathrm{s}$ in perpendicular to lamina by 10 mass $\%$ oxidation loss.

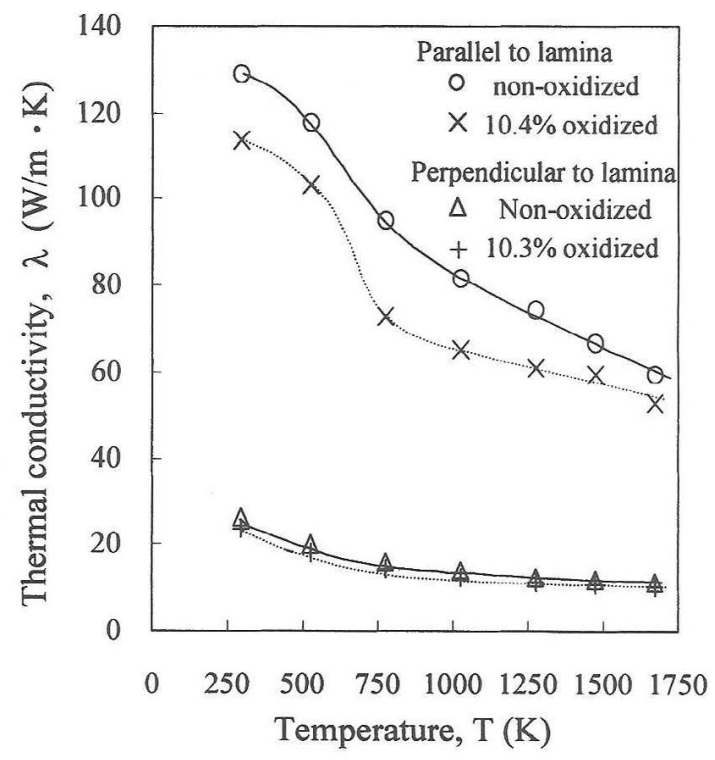

Fig.5. Temperature dependence of thermal conductivity of $2 \mathrm{D}-\mathrm{C} / \mathrm{C}$ composite before and after $10 \mathrm{mass} \%$ oxidation in both parallel and perpendicular to lamina. 


\subsection{Temperature Dependence of Thermal Conductivity}

Thermal conductivity of the composite is also plotted in Fig.5. Temperature dependence of thermal conductivity of the composite shows gentle slope in each direction. This is the cause of the increasing heat capacity of the carbon material increases from $0 \mathrm{~K}$ to more than $1500 \mathrm{~K}$ [16].

From a mechanism viewpoint, thermal conductivity of graphite is dominated by the phonon contributions. In general, thermal conductivity for isotropic material dominated by the phonon is explained by the product of density, specific heat, velocity of phonon $V_{\text {phonon }}$ and mean free path $\mathrm{L}_{\text {phonon }}$ as shown in Fig. 6 [17]. Measured data by several researchers of anisotropic graphite showed almost the same trend as shown in Fig.6, and measured peak temperatures were around room temperature $[15,18]$. The trend is thought to be affected by the phonon scattering mechanism due to crystal boundaries, anharmonic interaction with other phonons etc. [19] The obtained thermal conductivity in this study had the exponential trend and inverse trend in Fig.6, and had almost the same trend as the graphite; namely, it can be said that the thermal conductivity of the $\mathrm{C} / \mathrm{C}$ composite would be estimated on the basis of graphite data. Concerning this point, it will be necessary to conduct further modeling research on the $\mathrm{C} / \mathrm{C}$ composite in future.

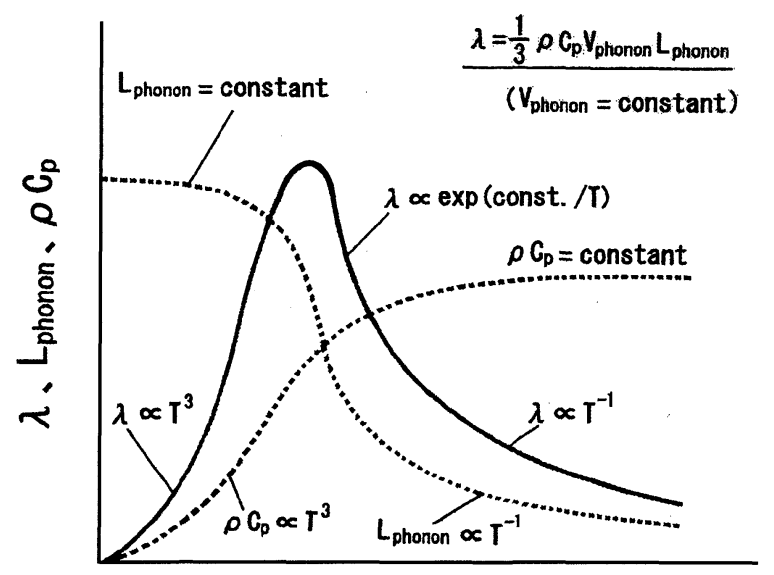

Temperature ( $\mathrm{T}$ )

Fig.6 Schematic drawing of thermal conductivity change with temperature for isotropic phonon contribution material [17].

\subsection{Change in Thermal Diffusivity by Air-oxidation}

Thermal diffusivity of the 2D-C/C composite in both parallel and perpendicular to lamina directions at temperatures of $773 \mathrm{~K}, 1273 \mathrm{~K}$ and $1673 \mathrm{~K}$ is shown as a function of oxidation loss in Fig.6. Solid lines mean evaluated ones by a least-squares method.
Thermal diffusivity reduced with increasing oxidation loss, and reduction of $10 \sim 20 \%$ and $5 \sim 9 \%$ within 11 mass $\%$ oxidation loss were observed in parallel to lamina and perpendicular to lamina, respectively. In parallel to lamina direction, thermal diffusivity tends to reduce as the increase of oxidation loss. On the contrary, in perpendicular to lamina direction, it decreased at the beginning of oxidation and not so changed with increasing oxidation. This different behavior of thermal diffusivity with oxidation loss could be explained from the laminar texture and oxidation behavior of the composite.

It is considered in parallel to lamina direction of this composite in Fig. 1 that the heat flow path is aligned in parallel, and so-called the "parallel model" can be applied. In case of perpendicular to lamina, so-called the "series model" can be applied. These models are described as following equations [20].

Parallel model (parallel to lamina in Fig.1):

$$
\begin{gathered}
\alpha_{\mathrm{para}}=\phi_{\mathrm{fL}} \alpha_{\mathrm{fl}}+\phi_{\mathrm{fT}} \alpha_{\mathrm{fT}}+\phi_{\mathrm{m}} \alpha_{\mathrm{m}}, \\
\phi_{\mathrm{fL}}+\phi_{\mathrm{fT}}+\phi_{\mathrm{m}}=1-V_{\mathrm{p}}, \phi_{\mathrm{fL}}=\phi_{\mathrm{fT}}=V_{\mathrm{f}} / 2 .
\end{gathered}
$$

Series model (perpendicular to lamina in Fig.1):

$$
\begin{aligned}
& \alpha_{\mathrm{perp}}^{-1}=\phi_{\mathrm{fT}} \alpha_{\mathrm{fT}}{ }^{-1}+\phi_{\mathrm{m}} \alpha_{\mathrm{m}}^{-1}, \\
& \phi_{\mathrm{fT}}+\phi_{\mathrm{m}}=1-V_{\mathrm{p}}, \quad \phi_{\mathrm{fT}}=V_{\mathrm{f}} .
\end{aligned}
$$

Here, $\alpha_{\text {para }}$ is the thermal diffusivity of parallel to lamina, $\phi_{\mathrm{fL}}$ the volume fraction of longitudinal direction fiber, $\alpha$ ft the thermal diffusivity of longitudinal direction of fiber, $\phi_{\mathrm{fT}}$ the volume fraction of transverse direction fiber, $\alpha_{\mathrm{fT}}$ the thermal diffusivity of transverse direction of fiber, $\phi_{\mathrm{m}}$ the volume fraction of matrix. $\alpha_{\mathrm{m}}$ the thermal diffusivity of matrix, $V_{\mathrm{p}}$ the volume fraction of pore, $\alpha_{\mathrm{perp}}$ the thermal diffusivity of perpendicular to lamina, and $V_{\mathrm{f}}$ the volume fraction of fiber. Here, $\phi_{\mathrm{f} L}$ and $\phi_{\mathrm{f} T}$ are considered to be almost equal and $V_{\mathrm{f}}$ is about 0.5 in this study.

Here, we propose a matrix-part dominated model. If we take into account of the pore volume produced by the oxidation loss, $B$, the volume fraction of pore $V_{\mathrm{p}}$ ' is given by

$$
V_{\mathrm{p}}^{\prime}=V_{\mathrm{p}}+k B, \quad k=\rho / \rho_{\mathrm{th}}
$$

where $\rho$ is the bulk-density $\left(1.63 \mathrm{~g} / \mathrm{cm}^{3}\right)$ and $\rho_{\text {th }}$ the theoretical density $\left(2.24 \mathrm{~g} / \mathrm{cm}^{3}\right)$ at the composite. Substituting $V_{\mathrm{p}}$ ' for $V_{\mathrm{p}}$ in Eqs. 5(b) and 6(b), then we can treat the oxidation loss in the parallel and series models.

Matrix of the composite is supposed to be well graphitized especially, at neighboring region of fiber bundles due to the stress graphitization [21]. Therefore, thermal diffusion in this composite is considered to be mostly governed by the matrix part, $\alpha_{\mathrm{m}}$ in Eq. 5a, especially at near the fiber bundle region. Next high thermal conductive part is the fibers in longitudinal 
direction, $\alpha_{\mathrm{fL}}$ in Eq.(5a) since PAN-fiber is supposed to be less graphitized [22] than the matrix. On the other hand, in the transverse direction, the thermal conductivity, $\alpha_{\mathrm{fT}}$ in Eqs.(5a) and (6a) is nearly one order less than that of longitudinal direction [22].

Here, we assume that $\alpha_{\mathrm{fL}}, \alpha_{\mathrm{fT}}$, and $\alpha_{\mathrm{m}}$ in Eqs. (5a) and (6a) are to be constant for the oxidized specimen, and assume that only matrix part is oxidized, namely, only $\phi_{\mathrm{m}}$ changes by oxidation. If we assume $\alpha_{\mathrm{m}} \approx \alpha_{\mathrm{fL}}$ and $\alpha_{\mathrm{fT}} \approx 1 / 10 \quad \alpha_{\mathrm{m}}$ in Eq (5a), the thermal diffusivity $\alpha_{\text {para }} / \alpha_{\mathrm{m}}$ is roughly estimated by

$$
\alpha_{\text {para }} / \alpha_{\mathrm{m}}=0.505-k B / 100 \text {. }
$$

If we also assume $\alpha_{\mathrm{fT}} \approx 1 / 10 \quad \alpha_{\mathrm{m}}$ in Eq (6a), the thermal diffusivity $\alpha_{\text {perp }} / \alpha_{\mathrm{m}}$ is roughly estimatd by

$$
\alpha_{\text {perp }} / \alpha_{\mathrm{m}}=\{20+1 /(0.23+k B / 100)\}^{-1} \text {. }
$$

From Eqs. (8) and (9), we estimated the thermal diffusivity at room temperature, and plotted with dotted line in Fig.7 (a) and (b). In parallel to lamina, calculated curve is well agreed with the experimental data; thermal conductivity linearly decreases as the oxidation loss proceeds. In perpendicular to lamina, there was some deviation between calculated and experimental data at the beginning of the oxidation. We can easily understand this different behavior comes from texture change due to the oxidation. The matrix part near the fiber bundle was oxidized preferentially from the beginning of the oxidation. The oxidation of this part much affects the thermal diffusivity in perpendicular direction, because the thermal diffusion path of this direction is eliminated greatly rather than that of parallel direction. Therefore, it is thought that the thermal diffusivity data decreased at the beginning of oxidation although the series model cannot imply this texture change due to the oxidation.

It is also found from Figs. 7(a) and (b) that the deviation of thermal diffusivity of oxidized specimen is rather large in parallel to lamina especially, at room temperature. This might be caused by the specimen thickness, namely, oxidation might produce in homogeneous texture in the specimen. Thick specimens are preferable to getting more homogeneous texture and small scatter of data, however, thin specimens are preferable to use in the thermal diffusivity measurement as mentioned in sec.2.2. Therefore, especially for oxidized condition, there might be no way to improve the scatter of data by the laser-flash method.
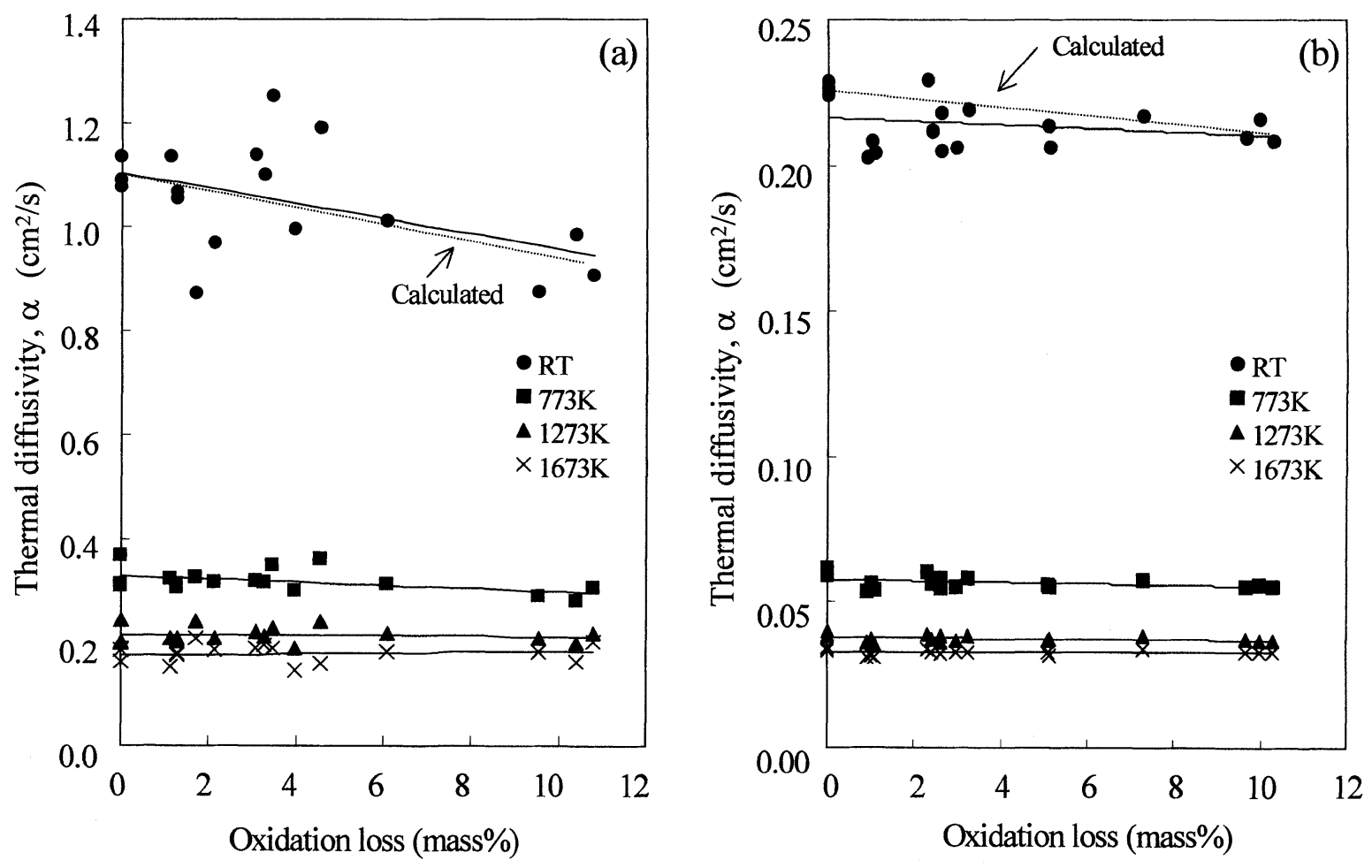

Fig.7 Change in thermal diffusivity of the $2 \mathrm{D}-\mathrm{C} / \mathrm{C}$ composite by air-oxidation. (a) parallel to lamina and (b) perpendicular to lamina. 


\section{CONCLUSIONS}

Effect of air-oxidation on the thermal diffusivity was studied using a nuclear grade 2D-C/C composite. Obtained results are summarized as follows:

(1) Oxidation loss of the composite preferentially occurred at the matrix part near the fiber bundle and wall surface of the pore.

(2) Thermal diffusivity tended to decrease gradually as the increase of oxidation loss in parallel to lamina, however, it decreased in the beginning of oxidation and not so changed with increasing oxidation loss in perpendicular to lamina direction.

(3) By applying parallel and series models, it was found that parallel mode fit quite well, however, the series model showed different behavior at the beginning of oxidation. This discrepancy was well understood by taking into account of the texture change due to the oxidation.

Acknowledgment - Authors would like to thank Mr. T. Hiraoka and Ms. J. Kondo of TOYO TANSO Co. Ltd. for their useful comments on the material.

\section{REFERENCES}

1. M. Eto, S.Ishiyama, and H.Ugachi, JAERI-Research 96-043 (1996)

2. M. Eto, S. Ishiyama, K. Fukaya, T.Saito, M. Ishihara, snd S. Hanawa, JAERI-Research 98-003 (1998).

3. S. Ishiyama, K. Fukaya and M. Eto, Trans. of J. Nucl. Soc., 41-10 (1999) 104.(in Japanese)

4. Y. Tachibana, T. Kojima, S. Hanawa, M. Ishihara, Proceedings of $7^{\text {th }}$ Int. Community for Composite Engineering (2000) 841.

5. M. Ishihara, T. Kojima and T. Hoshiya, Proceedings of
International Conference on Carbon in 2002, 15-20 September, Beijing, China (2002) H026.

6. T. Sogabe, M. Ishihara, S. Baba, T. Kojima, Y. Tchibana, T. Iyoku, T. Hoshiya and M. Yamaji, JAERI-Research 2002-026 (2002).(in Japanese)

7. E. Fitzer and L. M. Manocha, Carbon Reinforcements and Carbon/Carbon Composites, Chapter 7, Springer (1988).

8. J.Aihara and M.Ishihara, J. Soc.Mat. Sci. Japan, 49(2000) 1155 (in Japanese)

9. T.Maruyama and M.Harayama, J.Nucl.Mater. 195(192)44.

10. W. J. Parker, R. J. Jenkins, C. P. Butler and G. L. Abbott, J. Appl. Phys. 32, (1961) 1679.

11. A. T. D. Butland and R. J. Maddison, AEEW-R-815 (1972).

12. B. P. Jaldan and Y. K. Ras Carbon, 16, (1978) 175.

13. "Carbon Yougo-jiten" Agune-shoufusha, Ed. Carbon Society of Japan, (2000)131.(in Japanese)

14. E. Fitzer and L. M. Manocha, Carbon Reinforcements and Carbon/Carbon Composites,p.282, Springer (1988).

15. P. Wagner and L. B. Dauelsberg, Carbon, 6, (1968) 373.

16. J. M. Thomas, Chemistry and Physics of Carbon, Vol.1, Mercel Dekker, Inc., New York (1965) p.121.

17. T.Terai, New Introduction of Carbon, Ed. Carbon Society of Japan, REARIZE Inc.(1996) 47. (in Japanese)

18. B.T.Kelly, Chemistry and Physics of Carbon, Ed. P.Walker, Marcel Dekker Inc. 5(1969)195.

19. B.T.Kelly, Chemistry and Physics of Carbon, Ed. P.Walker, Marcel Dekker Inc. 5(1969)136.

20. A. Maezono, Ceramics, 29 (1994) 421. (in Japanese)

21. Y. Hishiyama, M. Inagaki, S. Kimura and S. Yamada, Carbon, 12, (1974) 24.

22. J. Matsui, Advanced Carbon Series, Ed. Carbon Society of Japan, REARIZE Inc. (1988)224. (in Japanese) 